\title{
Characterization of Liquid and Air Flow Behaviours in Twin Fluid Atomizer for Gas Turbine Combustor
}

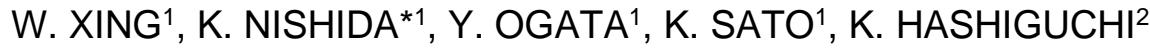 \\ ${ }^{1}$ Graduate School of Advanced Science and Engineering, University of Hiroshima, Japan \\ ${ }^{2}$ Research \& Innovation Center, Mitsubishi Heavy Industries, Ltd., Japan \\ *Corresponding author email: nishida@hiroshima-u.ac.jp
}

\begin{abstract}
A twin-fluid atomizer for gas turbine combustors was examined in the present study. The experimental and numerical methods were applied to analyse air-liquid collision and interacting behaviours in the atomizer. High-speed photography was used to investigate the spray characteristics. The atomizing air flow rate effects on the flow patterns in the atomizer, such as fluctuating and impinging to the inner wall of the atomizer, are elucidated. These results show that a liquid column is generated at the exit in the case of liquid-only injection, while an annular flow is generated in the case of twin-fluid injection. The expansion frequencies of the annular liquid film that occurs in the sprays are approximately equivalent to the fluctuation frequencies of the liquid column. The liquid jet development and breakup in the crossflow ambient were investigated, with and without the atomization air conditions.
\end{abstract}

Keywords: Fuel Injection, Twin-Fluid Atomizer, Spray Internal Flow, Gas Turbine Engine

\section{Introduction}

Gas turbine engines are widely used as power sources for the aerospace industry and thermal power plants. Recently, LNG or oil-fired gas turbine power plants attract attention world-widely as a coal-fired alternative. In a gas turbine combustor for a power plant, the atomization method called "Liquid Jet in Crossflow" is employed. Jet breakup mechanism and spray characteristics in crossflow have been extensively studied by many researchers [for example1-4]. These preceding outcomes taught us that due to the influence of crossflow, the liquid column breakup model was classified into four types: enhanced capillary breakup, bag breakup, multimode breakup, shear breakup. Furthermore, the trajectory of the liquid column and column breakup location were quantitatively analysed. However, there are still rooms for improvement of jet atomization. The atomization will directly affect emissions, combustion efficiency, and durability of combustor equipment.

Twin-fluid atomizers have been applied to many industrial fields for a long time, and even now the research is progressing. For example, the characteristics of the internal mixing atomizer for CWM (Coal Water Mixture) combustion were investigated [5-6]. A new internal mixing atomizer for low grade oil-fired boilers has developed [7]. Compared to the atomizers for the burner of the boiler, the gas turbine combustors, using "Jet in Crossflow" type atomization, are equipped with hole injectors whose diameters are small. The reason is that simpler structures are required. In our research, "a twin-fluid atomizer jet in crossflow" is attempted for the purpose of atomization improvement. A twin-fluid atomizer in which atomizing gas and liquid collide at a right angle is designed, and a series of research has been conducted [8-9].

In the present study, first, complicated liquid behaviours induced by atomizing air in the mixing port are studied by combining the results of experimental observation and numerical analysis. Next, the relationship between the internal flow and the characteristics of jets/sprays after injection is also clarified. In addition, to elucidate the important roles of atomizing air on the jets/sprays, breakup length under crossflow is analysed. 


\section{Experimental Method}

The details of twin fluid atomizer used in the present study is shown in Figure 1. The liquid was supplied from the upper side of the atomizer, and atomizing air was supplied from the left side. The liquid and the atomizing air collided at right angle in the mixing port. The diameter (Ø2.8) of the supply hole for liquid fuel and the diameter (Ø2.8) of the supply hole for atomizing air were same. And for the mixing port $(\varnothing 4)$, its cross-sectional area was designed to be equal to the sum of both cross-sectional areas of the liquid and the atomizing air. In this experiment, an enlarged model was used to observe details of the internal flow behaviours occurred in the atomizer. By the way, in some types of actual gas turbine combustor, mixing port diameters of atomizer are 1/3 1/2 times of the present mixing port. Liquid fuel and atomizing air collide at right angles. The twin fluid atomizer's material was made of transparent acrylic resin. The inner wall surface of the mixing port was carefully polished.

Figure 2 shows the schematic of the experimental equipment and the optical system. The blower (Showa Denki, EM-H22-R313) and wind tunnel provide a uniform crossflow to the observation area (150 mm $\times 150 \mathrm{~mm}$ (Square) $\times 300 \mathrm{~mm}$ (length)). The observation area of the tunnel material was made of transparent acrylic resin. The atomizer was installed on the ceiling of the observation area, and its exit sticked out $3 \mathrm{~mm}$ into the observation area.

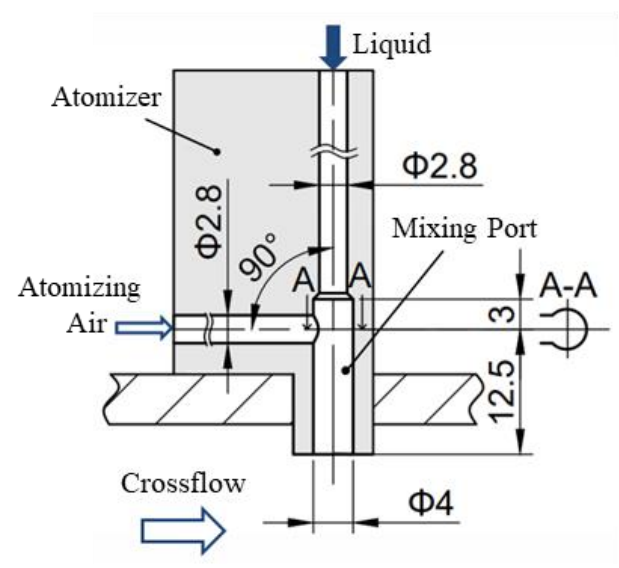

Figure 1. Details of twin-fluid atomizer

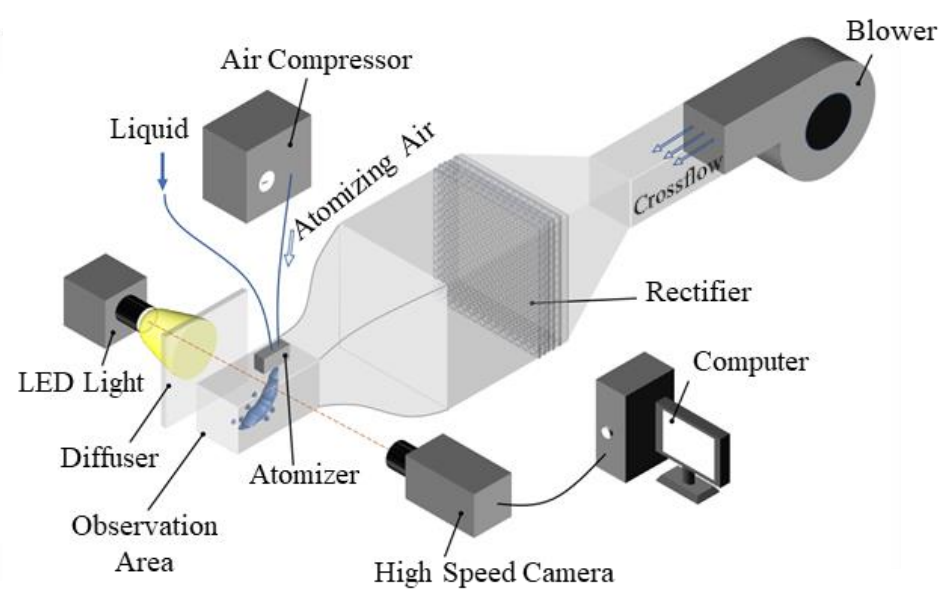

Figure 2. Experimental apparatus and optical arrangements

Tap water was used for the present experiment and the atomizing air was supplied from an air compressor (Makita, AC700). The flow rate of the liquid and the atomizing air was adjusted by a flow meter. The flow rate of the crossflow was controlled by an inverter. The range of crossflow velocity was from 0 to $15 \mathrm{~m} / \mathrm{s}$. The liquid flow rate was constant of $21.7 \mathrm{~g} / \mathrm{s}$. And the flow rate of the atomizing air was varied from 0 to $0.2 \mathrm{~g} / \mathrm{s}$.

When observing the internal flow and jets/sprays of atomizer, the LED light (Nac Image Technology, LLBK1-LA-W-0001) was continuously irradiated from one side of the atomizer or observation area, and the behaviours were photographed using a high-speed video camera (Photron, APX RS) and lens (Nikon, $105 \mathrm{~mm}$ or $200 \mathrm{~mm}, \mathrm{f} / 2.8$ ) from the opposite side. The shooting speed of the internal flow and jets/sprays was set to $5000 \sim 10000 \mathrm{fps}$, and the exposure time was changed from 6.54 to $20 \mu \mathrm{s}$. The image resolution was selected one of $256 \times 512$ and $512 \times 512$ pixels.

\section{Simulation Method}

Figure 3 shows an atomizer model that was developed for ANSYS Fluent. A hexahedral grid was used, and the mesh sizes were $0.035 \mathrm{~mm}$ and $0.05 \mathrm{~mm}$ at the liquid supply and the mixing port sections, respectively. A turbulent model Large-Eddy Simulation (LES) was used for the 
analysis, and the air-liquid interface was supplemented by the Volume Of Fluid (VOF) method. The physical properties, such as density and coefficient of viscosity, were averaged by the volume fraction $f$ of each computational cell's liquid phase. The governing equation is shown below.

$$
\rho=\rho_{l} f+\rho_{g}(1-f) \ldots \ldots \text { (1) } \quad \mu=\mu_{l} f+\mu_{\mathrm{g}}(1-f) \ldots \ldots \text { (2) } \quad \frac{\partial_{f}}{\partial_{t}}+u \cdot \nabla f=\frac{s_{f}}{\rho} \ldots \ldots
$$

Where, $\rho$ : the density, $\rho_{l}$ : the liquid density, $\rho_{\mathrm{g}}$ : the gas density, $f$ : the liquid phase volume fraction, $\mu$ : the viscosity coefficient, $\mu_{l}$ : the liquid viscosity coefficient, $\mu_{\mathrm{g}}$ : the gas viscosity coefficient, $u$ : the velocity and $S_{f}$ : the source term of $f$.

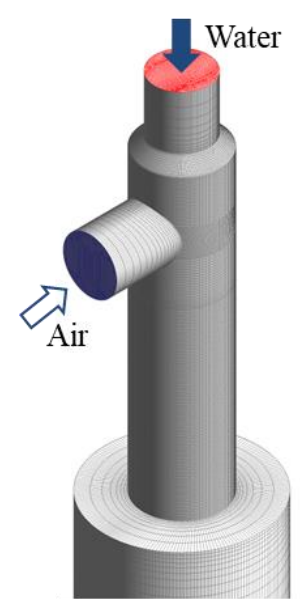

Figure 3. Simulation domain

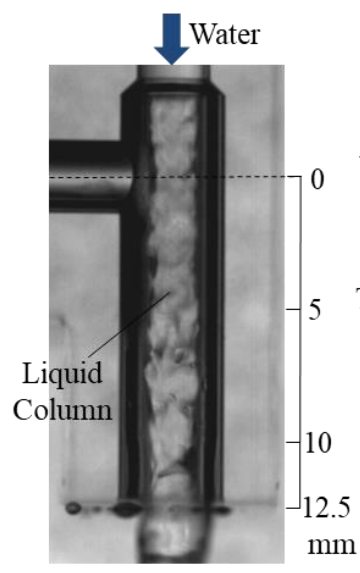

(a) Liquid-only injection $M_{a}=0 \mathrm{~g} / \mathrm{s}, \mathrm{GLR}=0$

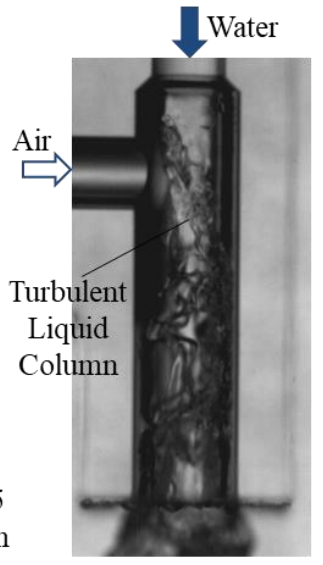

(b) Twin-fluid injection $M_{a}=0.2 \mathrm{~g} / \mathrm{s}, \mathrm{GLR}=0.92 \%$

Figure 4. Behaviours of liquid column in atomizer, $M_{w}=21.7 \mathrm{~g} / \mathrm{s}$ White area: water Black area: air, air/water interface

\section{Results and Discussion \\ Internal Flow of Twin-Fluid Atomizer}

Figure 4 shows internal flow behaviours obtained in the atomizer. Parts that look relatively bright indicate liquid fuel, and parts look dark show atomizing air. Figure 4(a) shows the result of liquid and atomizing flow rates of $M_{w}$ and $M_{a}$ are 21.7 and $0 \mathrm{~g} / \mathrm{s}$ respectively, that is liquidonly injection. The behaviour in figure $4(\mathrm{~b})$ shows a perturbated liquid column, which is obtained by adding atomizing air whose flow rate $M_{a}$ of $0.2 \mathrm{~g} / \mathrm{s}$. The GLR (Gas to Liquid Ratio) is equivalent to $0.92 \%$. In figure $4(\mathrm{a})$, the liquid column penetrates along the central axis of the atomizer. For the condition shown in figure 4(b), atomizing air and liquid column collide at right angle, and then surface of the liquid column deforms turbulently. Furthermore, due to the influence of atomizing air, the liquid column violently fluctuates from side to side and impinges on the inner wall of atomizer. At the exit of the atomizer, an annular liquid film flow with uneven thickness is formed.

Figure 5 shows the simulation results of the internal flow behaviours on the cross-sections of vertical along axis and the horizontal of the atomizer. These images illustrate the action of liquid within 2 microseconds. The red colour indicates the volume fraction of water to be 1 while bule colour indicates the volume fraction of the water to be zero, that is, the volume fraction of the air as 1 . Due to the influence of atomizing air, the liquid column swings from side to side and collides with the wall surface. The liquid column is attached to the right wall surface at the start time $t(\mathrm{~ms})$ in figure 5 , while the liquid column is attached to the left wall surface at the next time $t+1(\mathrm{~ms})$ and is attached again to the right wall surface at $t+2(\mathrm{~ms})$. These results suggest that such alternative liquid impinging from an annular liquid film around the inner wall at the exit of the atomizer. It is seen that the liquid film or the liquid mass on the 
side that collides with the wall surface is thick or massive, while the liquid film on the opposite side is quite thin.

From the results in the figure 5, the frequency of fluctuating liquid column in the mixing port of the twin fluid atomizer is approximately the same as the frequency at which the liquid column collides with the wall surface. And then, it is guessed that due to collision with wall surface, the annular flow generates at the atomizer exit, and it affects the behaviours of the liquid spray. So, it is necessary to analyse the fluctuation of the liquid column.

Figure 6 shows the definition of the 'width (apparent radius)' of the liquid column. The distance from leftmost boundary point to the central axis of the liquid column is obtained at a position $4 \mathrm{~mm}(=1 \mathrm{~d}$, d: diameter of mixing port) downstream from the collision part of air and liquid. Figure 7 (a) shows the time change of the liquid column width. The injection condition is same as those in figure 5. Figure 7(b) indicates the result of the Fast Fourier Transform (FFT) for fluctuation shown in figure $7(\mathrm{a})$. It is understood that the main frequency corresponds to a maximum peak appears at about $500 \mathrm{~Hz}$.

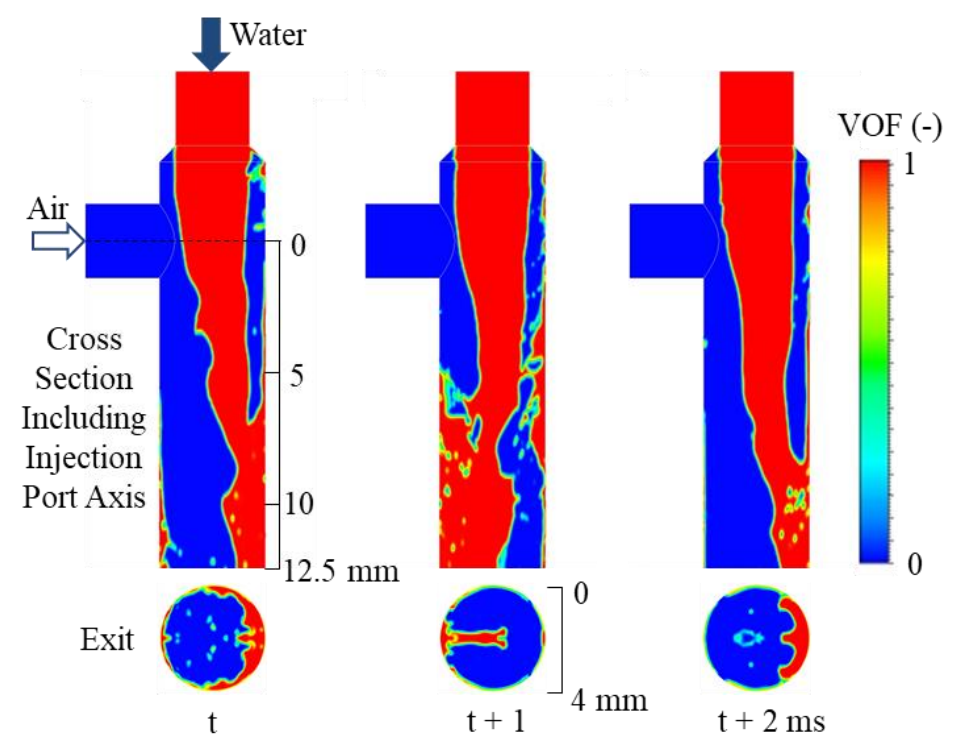

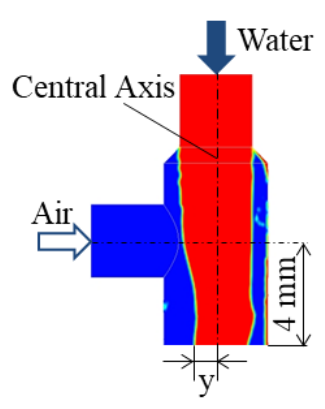

Figure 6. Definition of liquid column width y

Figure 5. Simulation results of turbulent liquid column and its impingement on inner wall of atomizer, $M_{w}=21.7 \mathrm{~g} / \mathrm{s}, M_{a}=0.2 \mathrm{~g} / \mathrm{s}, G L R=0.92 \%$

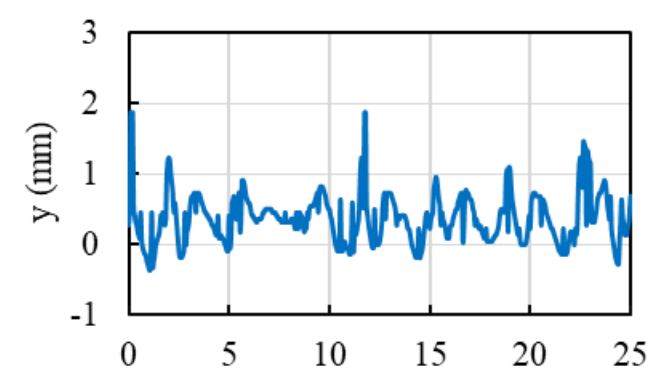

(a) Temporal variations of liquid column width

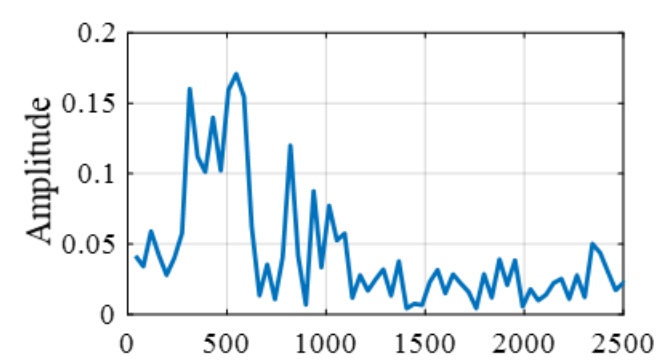

(b) Frequency spectrum of liquid column width $(\mathrm{Hz})$

Figure 7. Dynamic characteristics of liquid column width, $M_{w}=21.7 \mathrm{~g} / \mathrm{s}, M_{a}=0.2 \mathrm{~g} / \mathrm{s}, G L R=0.92 \%$

\section{Liquid Jet/Spray in Still Air Liquid Jet/Spray Behaviours}

Instantaneous images of (a) liquid-only and (b) twin-fluid injection in still air are shown in figure 8. The liquid flow rates of $21.7 \mathrm{~g} / \mathrm{s}$ are same for both injections (a) and (b), but no atomizing air for (a) and with atomizing air for (b). The obvious difference between the two behaviours provides importance of atomizing air in jet/spray dispersion. The left image (Fig.8(a)) shows 
one liquid column is ejected from the atomizer. The right image (Fig.8(b)), which corresponds to GLR $0.92 \%$, shows a disturbed annular liquid film pop-ruptures and results in ligaments and droplets. By adding the atomizing air into the mixing port, the liquid column can be forcibly deformed into a turbulent liquid film. Film wise liquid is considered easy to be disintegrated.
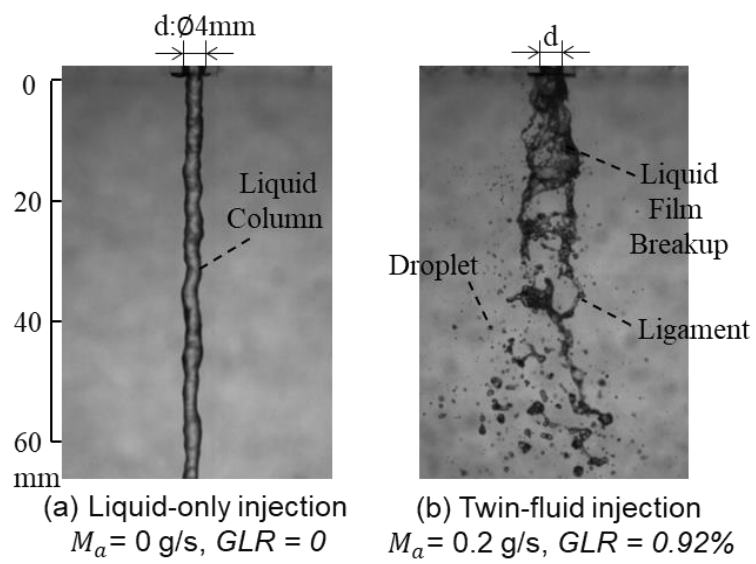

Figure 8. Liquid jet/spray in still air (no crossflow), water flow rate $M_{w}$ is $21.7 \mathrm{~g} / \mathrm{s}$ for both of (a) and (b)

\section{Characteristics of Liquid Behaviours Immediately After Twin-Fluid Injection}

Figure 9(b) shows the enlarged images of liquid behaviours within 3.2 milliseconds in the neighbourhood of the exit of the atomizer in twin-fluid injection. These luminance-like images are obtained by a background subtraction method. At the same time, the simulation results of corresponding horizontal plane at the atomizer exit are shown in figure 9(a). The injection conditions are follows; the liquid flow rate of $21.7 \mathrm{~g} / \mathrm{s}$, atomizing air flow rate of $0.2 \mathrm{~g} / \mathrm{s}$ and GLR of $0.92 \%$. In the twin-fluid injection, the liquid column fluctuates violently and collides with the inner wall of the atomizer, resulting in injection of a liquid film with an uneven liquid film thickness. In all images shown in figure 9, the darker areas indicate that the liquid film is relatively thin, on the other hand the brighter areas illustrate that the liquid film is relatively thick. Thus, difference of liquid film thickness just after injection are observed for the small squares of (1) and (2) at the exit of the atomizer. All squares are sized to $2 \mathrm{mmX} 2 \mathrm{~mm}$. In the luminance-like images appeared in the red (1) and bule (2) squares of figure 9, light and dark are alternatively and quickly repeated.

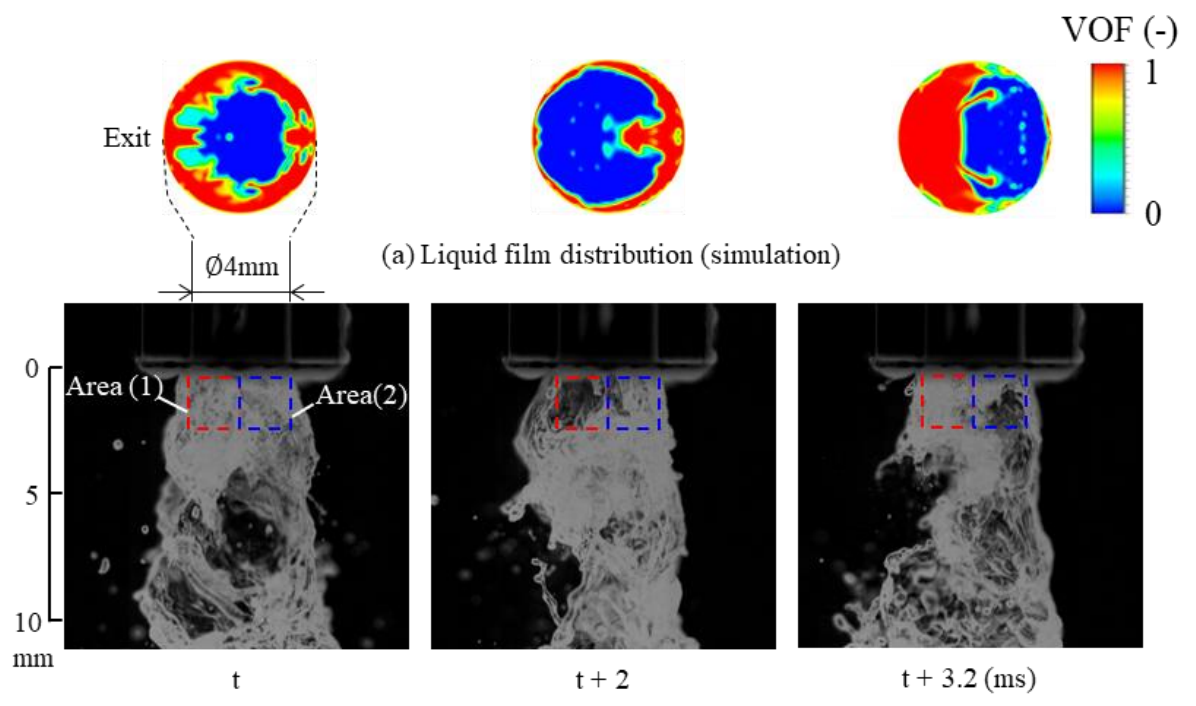

(b) Enlarged images of spray (experiment)

Figure 9. Luminance-like images of time change behaviours at atomizer exit $M_{w}=21.7 \mathrm{~g} / \mathrm{s}, M_{a}=0.2 \mathrm{~g} / \mathrm{s}, \mathrm{GLR}=0.92 \%$ 
Figure 10 compares the results of Fast Fourier Transform (FFT) analysis of the luminance fluctuations between the areas (1) and (2) in figure 9. The dominant frequency appears at approximately $500 \mathrm{~Hz}$ at both (1) and (2). This dominant frequency of $500 \mathrm{~Hz}$ is almost same as it observed in liquid column fluctuation as shown in figure 7(b). Figure 11 shows obvious agreement between the two dominant frequencies. The statistical results above suggest that the formations and properties of liquid film at the exit of the atomizer are originated in behaviours of the liquid column upstream in the mixing port.

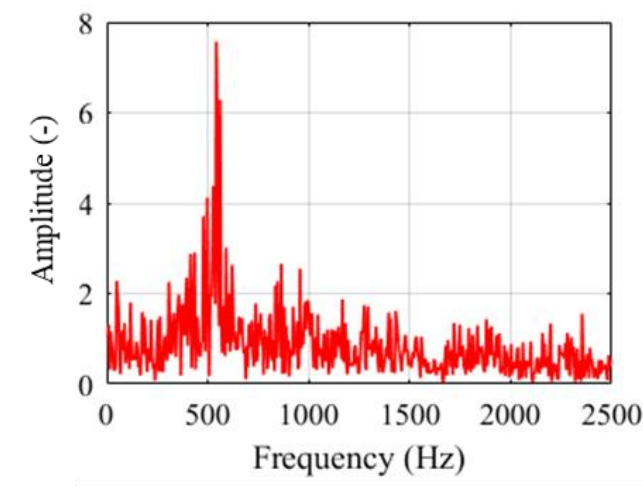

(a) Area (1)

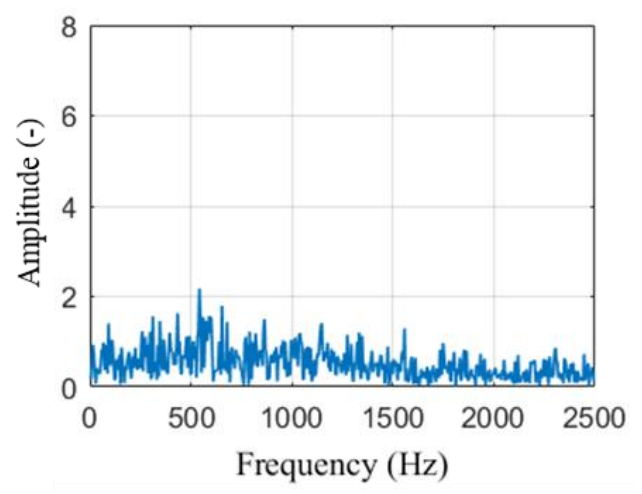

(b) Area (2)

Figure 10. FFT results of luminance, $M_{w}=21.7 \mathrm{~g} / \mathrm{s}, M_{a}=0.2 \mathrm{~g} / \mathrm{s}, G L R=0.92 \%$

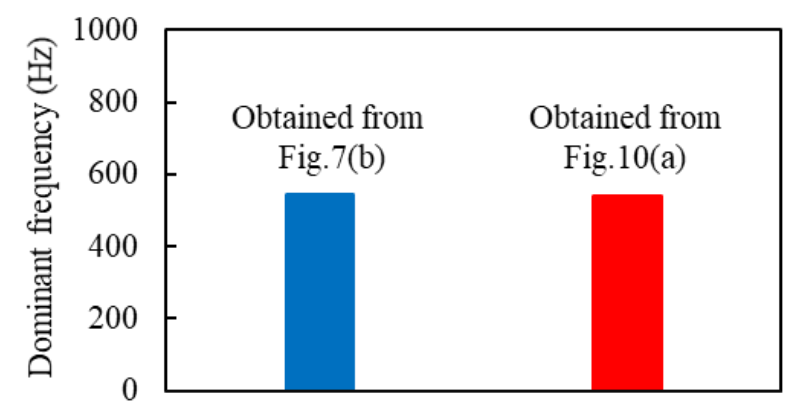

Figure 11. Comparison of dominant frequencies for fluctuations of Fig.7(b) liquid column and Fig.10(a) liquid film at exit port of the atomizer

\section{Liquid Jet/Spray Characteristics in Crossflow Liquid Jet/Spray Breakup Mechanism}

Figure 12 shows the liquid jet/spray behaviours in crossflow. Figure 12(a) and (b) correspond to liquid-only injection and twin-fluid injection, respectively. The crossflow velocity $U_{x}$ is constant of $15 \mathrm{~m} / \mathrm{s}$. When the liquid only is injected, waves are generated on the surface of liquid column by means of the crossflow, as shown in figure 12(a). Then, the waves grow into a bag and breakup, producing ligaments and droplets. These behaviours are well known, and their details have been investigated [2]. For the twin-fluid injection, an annular flow is injected from the atomizer exit and its film grows like tiny balloon, as shown in figure 12(b). Under the influence of crossflow, the annular liquid film breakups into ligament, resulting in coarse and fines. Such examples indicate apparent difference between liquid-only and twin-fluid injections in crossflow. Compared to an incomplete atomization as shown in figure 12(a), figure 12(b) has a larger liquid jet/spray spread and produces a larger number of droplets. Furthermore, deep penetration along injecting direction across crossflow is clearly seen for the twin-fluid injection. From the above jet/spray characteristics, it was found that profiles and trajectories of jet/spray can be strongly dominated by atomizing air supplying or not. 


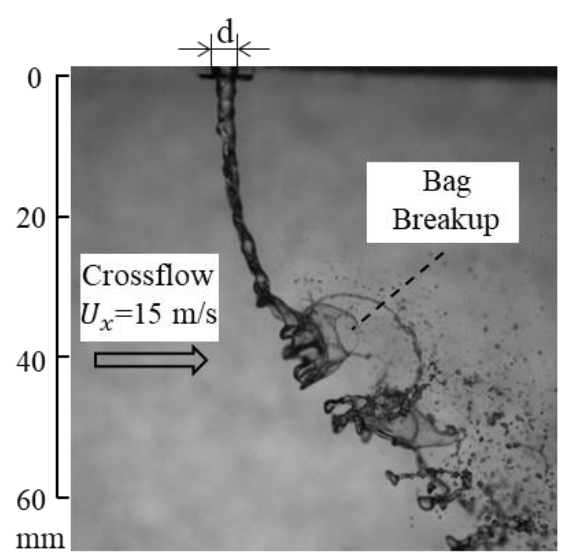

(a) Liquid-only injection, $M_{a}=0 \mathrm{~g} / \mathrm{s}, G L R=0$

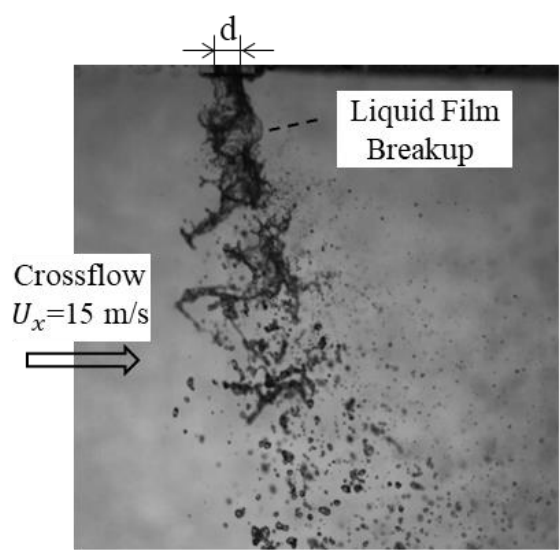

(b) Twin-fluid injection, $M_{a}=0.2 \mathrm{~g} / \mathrm{s}, G L R=0.92 \%$

Figure 12. Liquid jet/spray in crossflow, $M_{w}=21.7 \mathrm{~g} / \mathrm{s}, U_{x}=15 \mathrm{~m} / \mathrm{s}$

\section{Breakup Length of Liquid Jets}

In the present study, fluctuating actions of liquid jet breakup are investigated using high-speed images and their processed ones. Figure 13 shows one instant image after processing and the definition of the apparent breakup length $L_{b}$. This image example was captured under the conditions below; the flow rate of liquid is $21.7 \mathrm{~g} / \mathrm{s}$, the flow rate of atomizing air is $0.2 \mathrm{~g} / \mathrm{s}$, and the velocity of crossflow is $15 \mathrm{~m} / \mathrm{s}$. The background is differentiated by the MATLAB code, and the image is converted into a binary image by the Otsu's method [10]. Smaller areas are removed, and then largest areas are left. Resulted that the distance from the atomizer exit to the farthest boundary point downstream is obtained as the apparent jet breakup length.

Figure 14 shows the comparison of the time changes of the breakup length of liquid jets between liquid-only and twin-fluid injections. For both injections it is seen that the apparent breakup length $L_{b}$ increase at a constant incline, reach tops and decrease with relatively sharper inclines. It is found that such nearly periodical fluctuations repeat for both injections and a collapse in wave shape is somewhat large for twin-fluid injection. It is considered that irregularly deformed wave shape is features not to be missed to know properties of the twinfluid injection. The lengths $L_{b}$ by twin-fluid injection are almost close to half of those by liquidonly injection. This result clearly indicates that twin-fluid injection provides good atomization compared with liquid-only injection.

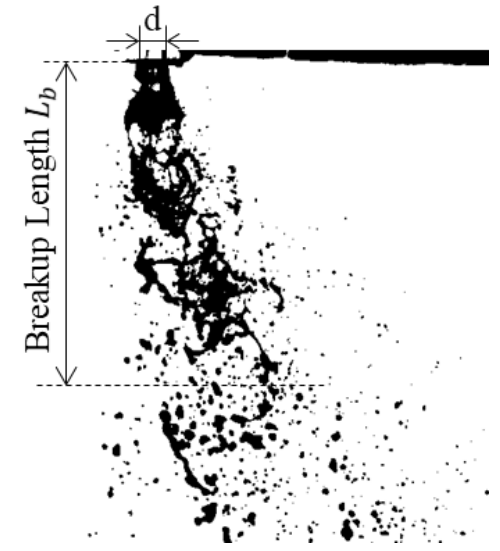

Figure 13. Definition of spray breakup length $M_{w}=21.7 \mathrm{~g} / \mathrm{s}, M_{a}=0.2 \mathrm{~g} / \mathrm{s}, U_{x}=15 \mathrm{~m} / \mathrm{s}$

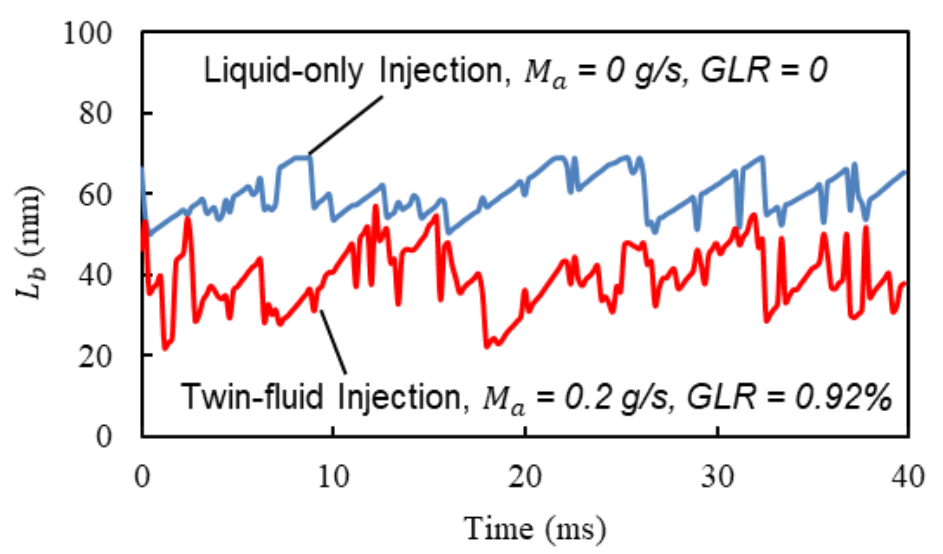

Figure 14. Time change of liquid jet/spray breakup length $M_{w}=21.7 \mathrm{~g} / \mathrm{s}, U_{x}=15 \mathrm{~m} / \mathrm{s}$ 


\section{Summary and Conclusions}

Experimental and CFD simulation research were conducted to clarify the internal flow behaviours of atomizer with vertically colliding of air and liquid. Furthermore, experimental studies were carried out to examine details of breakup mechanism and spray characteristics in still air and in crossflow. The conclusions obtained are follows;

(1) Within the range of the injecting condition in the present studies, a liquid column appears in the liquid-only injection. On the other hand, in a twin-fluid injection, an annular flow is injected.

(2) Relating to the twin-fluid injection, the liquid column violently swings and alternately collides with the inner wall surface of the mixing port.

(3) At a point of the exit of the mixing port, liquid film thickness alternately increases and decreases. That is, state of liquid film is periodically changing at the atomizer exit.

(4) The fluctuation of the liquid column in the mixing port strongly relates to the change of the liquid film thickness at the exit of the injection, and the dominant frequency of the liquid column fluctuation is almost the same as the frequency of the changing liquid film thickness. Furthermore, the fluctuation is observed in liquid film formation of jet immediately after injection. These notable behaviours are considered to be essential to liquid breakup for the twin-fluid atomizer used in the present study.

(5) When liquid-only is injected in a crossflow, the liquid column becomes bag-shaped one and then ruptures. However, when twin-fluid injection, the turbulent liquid film disintegrates to ligaments and droplets.

(6) Compared with liquid-only injection, the breakup length of twin-fluid injection is shortened.

\section{Acknowledgments}

The authors gratefully acknowledge supports from the HIROTEC Company and the Phoenix Factory of Hiroshima University. Furthermore, the authors express gratitude to Mr. Jun TODA who was devoted to experiments and data processing as the senior student.

\section{References}

[1] Wu, PK., Kirkendall, KA., Fuller, RP., Nejad, AS., 1998, Journal of Propulsion and Power, 14(2), pp.173-182.

[2] Ng, C.-L., Sankarakrishnan, R., Sallam, K.A., 2008, International Journal of Multiphase Flow,34(3), pp.241-259.

[3] Wang, Q., Mondragon, U.M., Brown, C.T., McDonell, V.G., 2011, Atomization and Sprays, 21(3), pp.203-219.

[4] Noda, J., Miyazaki, K., Aoki, K., Hashiguchi, K., 2020, Mitsubishi Heavy Industries Technical Review, 57(1), pp.1-6.

[5] Sato, K., Okiura, K., Baba, A., Shoji, K., Akiyama, I., 1987, The Japan Society of Mechanical Engineers, 53(493), pp.2890-2895.

[6] Sato, K., Okiura, K., Baba, A., Shoji, K., Akiyama, I., 1987, The Japan Society of Mechanical Engineers, 53(494), pp.2995-3002.

[7] Hashiguchi, K., Yamane, F., Fuji, H., Sato, K., Nishida, K., 2019, Atomization and Sprays, 29(2), pp.161-176.

[8] Xing, W., Hashiguchi, K., Sato, K., Nishida, K., Ogata, Y., 2020, Atomization: journal of the ILASS-Japan, 29(98), pp.84-94.

[9] Xing, W., K., Nishida, Ogata, Y., Sato, K., Hashiguchi, K., 2020, Conference of ILASSJAPAN 29: B-224.

[10] Otsu, N., 1979, IEEE Transactions on Systems, Man, And Cybernetics, 9(1), pp.62-64. 